\title{
HUMANITARIAN ENGINEERING EDUCATION: EXAMPLES
}

\author{
Witold Kinsner \\ Cognitive Systems Laboratory \\ Department of Electrical and Computer Engineering \\ University of Manitoba, Winnipeg, MB, Canada R3T 5V6 \\ witold.kinsner@umanitoba.ca
}

\begin{abstract}
Recent developments in mathematics, science, engineering and technology over the last several decades have made it possible to transform technology from machine-oriented (designed to increase productivity and quantification) to more human-centric (to simplify interaction with technology and improve the well-being of individuals). Technology is being positioned to be moved from a privilege to a social benefit. Such humanitarian technology (HT) can help at several levels, including: (i) natural disasters (such as fires, storms, tornadoes, tsunamis, earthquakes), (ii) humanitarian disasters (genocides, wars, non-democratic elections, injustice), (iii) developing countries (water, food, shelter, energy, sanitation, health, (iv) developed countries (the poor, seniors, people with physical or mental disabilities, or under-represented). Since, in all those levels, information gathering and distribution is considered as important as water, food and medicines in disasters, it must be considered as an ecosystem.

The development of a good HT has many scientific, engineering, technological and social challenges. One of the important challenges is education. How do we teach the new generation of humanitarian design engineers? This paper describes one approach used in Manitoba.
\end{abstract}

Keywords: Humanitarian engineering education; humanitarian technology (HT); HT definitions; HT organizations; HT scope; HT challenges.

\section{INTRODUCTION}

\subsection{New Vision of Humanitarian Technology}

Recent developments in mathematics, science, engineering and technology over the last several decades have made it possible to transform technology from machine-oriented (designed to increase productivity and quantification) to more human-centric (to simplify interaction with technology and improve the well-being of individuals). Technology is being positioned to be moved from a privilege to a social benefit. Such humanitarian technology (HT) can help at several levels, including: (i) natural disasters (such as fires, storms, tornadoes, tsunamis, earthquakes), (ii) humanitarian disasters (genocides, wars, non-democratic elections, injustice), (iii) developing countries (water, food, shelter, energy, sanitation, health, (iv) developed countries (the poor, seniors, people with physical or mental disabilities, or under-represented). Since, in all those levels, information gathering and distribution is considered as important as water, food and medicines in disasters, it must be considered as an ecosystem.

This new vision of technology has been embraced by the Institute of Electrical and Electronics Engineers (IEEE) for the last several years. Other organizations are also becoming more sensitive to this fundamental problem. For example, The Canadian Engineering Accreditation Board (CEAB) and the American Accreditation Board for Engineering and Technology (ABET) have already mandated university undergraduate courses on Technology and Society for years now, as well as the final-year group design projects (capstone projects) in the last decade.

At the practitioners level, international efforts are being made to bring the extensive engineering expertise to the HT designers and implementers. For example, the Humanitarian Technology Challenge (HTC) was introduced by IEEE, United Nations (UN) and Vodaphone Foundations in 2008 to reduce and eradicate poverty. HTC now includes the Engineering for Change (E4C) established by the American Society for Mechanical Engineers (ASME). IEEE also introduced the Humanitarian Technology Network (HTN), the Special Interest Group on Humanitarian Technology (IEEE SIGHT), the World-Wide Education for the HTC (we-HTC), the Teachers-In-Service Program (TISP), the Engineering Projects in Community Service (EPICS), as well as TryEngineering, TryComputing, and TryNano.

Many other organizations are also involved, including the UN Office for the Coordination of Humanitarian Affairs (OCHA), Oxford Committee for Famine Relief (Oxfam), Red Cross, Red Crescent, Save the Children, BBC World Service Trust, Thomson-Reuter Foundation, Humanitarian Media Foundation, and International Media Support.

\subsection{Humanitarian Engineering}

Before proceeding to giving examples of humanitarian engineering education, we should define Engineering and 
Humanitarian Engineering (HumEng). There are wellestablished definitions of Engineering. For example, "Engineering is the application of science through design, implementation, testing and introduction of systems, processes and other artifacts to improve productivity and the quality of life [4]. In the past, engineering as a profession has been driven mostly by external values, as articulated by Thomas Tredgold (1788-1829) in 1828 [17] "Engineering is the art of directing the great sources of power in nature for the use and convenience of man, ... as the means of production ..." This concept has moved later from "use and convenience" to include "public safety, health, and welfare."

Humanitarianism is a mirror that reflects on the "use and convenience" as well as the "public safety, health and welfare." Engineering and humanitarianism have never been in conflict in principle, as both concepts experienced parallel developments.

There are many definition of humanitarian engineering (HumEng) that have been evolving in different contexts over the last several years. Popular definitions say that "the field of HumEng describes the application of engineering and technology for the benefit of disadvantaged communities," or that "HumEng is intended to improve quality of life and disaster recovery."

A more comprehensive definition resulted from the study of VanderSteen [16, p.8] who defined HumEng as "the application of engineering skills specifically for meeting the basic needs of the people, while at the same time promoting human (societal and cultural) development." Another definition of HumEng is provided by Mitcham and Muñoz [11, p. 27] as "the artful drawing on science to direct the resources of nature with active compassion to meet the basic needs of all, especially the powerless, poor, or otherwise marginalized."

It is clear that HumEng should not be seen as another discipline, but as a philosophy on how engineering should be taught, so that practising engineers could be humanitarian engineers who could provide a balance between basic human needs, technical excellence, economic feasibility, sustainability, ethical maturity, and cultural sensitivity to enrich the human condition. This human-centric approach differs fundamentally from a technology-centric approach to engineering.

\subsection{Humanitarian Engineering Education}

An increasing number of papers and books is being dedicated to humanitarian technology and its education. For example, Collins and Halverson [3] propose rethinking how students are taught in the age of global connectivity and new technologies. Kinsner and Pear [9], [10], [15] developed a computer-aided personalized system of instruction, CAPSI, based on Fred Keller's PSI in order to personalize the educational process through proctoring and personalized rate of learning. CAPSI could be used as a tool in the delivery of humanitarian education. Amadei and Wallace [2] indicate that the top-down approaches for delivering aid to underdeveloped nations have not produced satisfactory results, and that engineers have not been involved in the technical aspects of these efforts. Amadei and Sandekian [1] argue that the engineering profession must embrace a new mission statement to contribute to the building of a more sustainable, stable, and equitable world. Moskal and her colleagues [12] describes a Humanitarian Engineering program at the Colorado School of Mines. Passino [14], [13] proposes various strategies to increase educational activities related to humanitarian education. The IEEE Global Humanitarian Technology Conference, GHTC, and the International Humanitarian Technology Conference, IHTC, are dedicated to various developments of humanitarian technology for the developing countries, and also address some educational issues (e.g., [18]).

The shift from consumer product-oriented research and development (R\&D) to HT has major ramifications not only on how we teach university students, but also provides a tremendous opportunity on how we rekindle the quest for knowledge of the pre-university students, including high schools and primary schools.

In order to expand experiential learning (EL), we have introduced many activities for both university and high-school students. Our university EL engagement activities include: multi-tier laboratories [7], industrial capstone projects [8], and complex design projects such as the T-Sat [6] and a wildlife conservation UAV. To attract the next generation of designers, outreach to high-school and primary-school students must also be conducted through hands-on activities, including (i) Open-house days (shopping malls, university), (ii) workshops (e.g., electronics, microcontrollers, rockets, and robotics), (iii) high-altitude balloon launching, (iv) teaching-teacher workshops, (v) summer space discovery camps [5], (vi) Aboriginal high-school student exploratory camps, and (vii) direct mentorship. Such activities should not be conducted in isolation, but be part of an international engagement.

This paper describes activities conducted towards both pre-university and university students in Manitoba over the last thirty years.

\section{UNIVERSITY ENGAGEMENT}

\subsection{Motivation}

Engagement of university and college students in hands-on activities that go much beyond classroom learning is essential in the new pedagogy, as it provides young professionals not only with more skills and appreciation of "things that work and work green," but also prepares them to engage the next generation of young professionals who are still in high schools. Due to its extent, this task cannot be done by experienced professors and instructors in the 
classroom only. Our specific activites include: (i) Canadian Satellite Design Challenge (TSat1 and TSat2; outreach), (ii) Young Engineers' Satellite (YES2) project, (iii) WinCube project, (iv) UAV for Humanitarian Purposes, (v) UMARS outreach through workshops (antenna design and construction), (vi) UMIEEE workshops, (vii) NASA Apps Challenge, (viii) Xtreme Programming (IEEE, ACM), and (ix) UNESCO Vocational Training (UNEVOC). This paper focuses on some of the projects only.

\subsection{Nano-Satellite Design}

An unprecedented example includes our satellite design and implementation project that was conducted under the umbrella of the Canadian Satellite Design Challenge instituted in October 2010. The University of Manitoba project team was assembled to design, build, and test a fully functional nano-satellite (TSat1) to perform two scientific experiments in low-Earth orbit (LEO). The team included over 100 undergraduate and graduate students from five faculties and 16 departments, as well as over 50 advisors from academia, aerospace industry, business, military, and government. The satellite team has reached over 4,200 students in high schools and community through seminars and workshops.

This work extended the nature and range of the programs our University offers by providing a very challenging project that allows them to use the theoretical knowledge with practical experience and linkages to industry. Another result of this project was the new University of Manitoba Space Applications and Technology Society (UMSATS) established in 2011.

\subsection{Other Space-Related Projects}

Other examples of space-related projects include the YES2, WinCube, the controlled ascent/descent highaltitude balloon (CAD-HAB) project, several UAV projects, and a Satellite Ground Station.

2.3.1 The YES2 Project: This project involved the development of a system to bring time-sensitive experiments from a LEO satellite to ground without rocket fuel. The project involved students from 60 countries, concentrating on different subsystems of YES2. The students worked with different R\&D companies. Team Canada worked with the Netherlands, Germany and Spain. The project was fully functional, and was tested in zerogravity on a parabolic flight.

2.3.2 The WinCube Project: This project involved several teams of the final-year group design (Capstone) project. The WinCube Data Handling and Control (DHC) subsystem was very innovative and successful.
2.3.3 The CAD-HAB Project: The controlled ascent/descent (CAD) high-altitude balloon (HAB) project was to design and implement a prototype of a HAB that could ascent and descent in a controlled manner. Such balloons are used for near-space exploration (measurement of various parameters such as temperature, pressure, solar and cosmic radiation, wind-stream velocity and direction). Our objective is to use the vehicle as a testing laboratory for various experiments and electronic circuits designated for a low-Earth orbit (LEO) spacecraft. The payloads are expensive, and should be retrieved safely.

Regular HABs ascent to about 100 to 120 thousand feet, and burst there because of the low pressure (close to a Marsian atmosphere, around 1\% of the Earth's sea-level pressure). Following a free-fall descent (until the atmosphere becomes denser), a parachute deploys, and the payload lands somewhere. It is usually difficult to retrieve it.

The CAD-HAB could also prolong the exposure to near-space conditions for a longer time, and return without the parachute, or deploy the parachute without the free fall (when the global-positioning system, GPS, tracking is usually lost).

2.3.4 The $\boldsymbol{U} \boldsymbol{A} \boldsymbol{V}$ Projects: The UAV project is intended to develop a multi-copter to deliver food and medicine to remote locations in Manitoba. It involves a new type of attitude determination and control (ADC) subsystem, as well as a new kind of data communication between ground and the UAV. Another UAV is being developed to help reduce poaching of rhinoceros and other animals in Africa.

2.3.5 Satellite Ground Station: A Satellite Ground Station was developed to provide tracking, communications and control capabilities for several of the projects just described.

\subsection{Competitions and Contests}

Several other examples include competitions and contests. Students become engaged in problem solving under extreme time constraints and endurance pressure.

2.4.1 Extreme Programming: The yearly IEEE Xtreme Programming contest is designed to engage university and college students from around the globe in a continuous 24hours problem solving, using any specified programming language. The 2013 contest involved 30 students organized in 10 teams from the University of Manitoba and Red River College. The students placed well among the 3000 other individuals participating in the contest.

Our university and college students also participate in other contests, such as the multi-level Association of Computing Machinery (ACM) Programming Contest. 
2.4.2 Extreme Design: Our university students, developers, engineers, scientists, and space enthusiasts also participate the International Space Apps Challenge (ISAC). The ISAC is a two-day hackathon where the participants collaborate to solve problems selected by NASA and intended to address global needs for both life on Earth and life in space. The objective is to produce open-source solutions by bringing together people of all ages and different areas of expertise to work together to solve combinations of software challenges, open hardware challenges, citizen science presentations, and data visualization tools. Participants work in teams, and collaborate with individuals from around the world to develop their solution. At the end, the best two solutions from any venue are submitted to NASA for judging, with the winners receiving international recognition and prizes. We have organized several such events. The latest was completed in April 2014.

\subsection{College Education}

A fundamental mission of a university engineering program is to develop professionals capable of solving engineering problems and design, implement, deploy, and maintain systems that do not harm others and the environment. A mission of a college and a vocational school is to develop technical professionals who help in the above activities.

2.5.1 UNEVOC: In 1999, the United Nations Educational, Scientific and Cultural Organization (UNESCO) established the International Centre for Technical and Vocational Education and Training (UNEVOC) "to develop policies and practices concerning education for the world of work and skills development for employability and citizenship." A UNEVOC branch was established at this university to address the issue of (i) how technical and vocational education (TVE) pedagogy is different from general university pedagogical techniques, (ii) how adaptation of an outcomes-based education (OBE) model (closely linked to a business model of Total Quality Management) affects the delivery of TVE in educational institutions, and (iii) how experiential learning is different from vocational training.

Discussions of such issues involve students and professors from engineering, science and education, as well from the Centre for the Advancement of Teaching and Learning (CATL, formerly University Teaching Services) whose mandate is to assess trends in higher education such as experiential learning, blended and on-line learning, and innovative pedagogical approaches.

\subsection{Extended Education}

Another opportunity to interact with various groups of students has been a course on Basic Radio Qualifications Certificate offered to students from the university, high schools, and the community at large. The course focuses on the three fundamental aspects of amateur radio: (i) operations for personal communications, (ii) service in natural disasters and community events, and (iii) research to develop new radio communications techniques.

\section{Pre-University Engagement}

\subsection{Overview}

The pre-university engagement outreach addresses (a) high-school students, (b) Aboriginal students, and (c) primary students. Our specific activities include: (i) enrichment workshops on computing and algorithmic thinking in primary schools, (ii) Mini-University (Electrical and Computer Engineering module; amateur radio for highschool students; foxhunts), (iii) Peguis First Nation Science and Engineering and Technology Symposium, SETS (hands-on workshops on robotics), (iv) Verna Kirkness Discovery Camps for Indigenous Students, (v) Space Camp, (vi) the Teachers-In Service (TISP, with Teaching Teachers Workshops) program, and the Engineering Projects in Community Service (EPICS), and (vii) direct mentoring to students. This talk will focus on the Space Camp, Verna Kirkness Program and Peguis First Nation SETS.

\subsection{Discovery Camps}

3.2.1 Space Camp For High-School Students: The annual Space Camp has been offered at the University of Manitoba since 2008. This one-week event is designed for Grade 9 to 11 students to engage them in problem identification, problem solving, design, modelling, implementation, verification, and testing in extreme environments. The students build and launch rockets, build and test robots, use satellite radio, and are exposed to the local aerospace industries.

\subsubsection{Discovery Camp for Indigenous Students: For} the fist time in 2013, another one-week Discovery Camp for Indigenous Students was developed and administered under the umbrella of the Verna Kirkness Program in the Faculty of Engineering. This activity is intended to increase access of Indigenous students to our programs. Another form to reach such students in Manitoba was the two-day Peguis First Nation Science, Technology and Engineering Symposium offered at the University of Manitoba in the past. It provided many presentations, including major workshops on robotics.

\subsection{Student Organizations}

A very effective way to reach many university and high-school students either separately or simultaneously is 
the University of Manitoba Amateur Radio Society (UMARS), and University of Manitoba IEEE Student Branch (UMIEEE), the IEEE Women in Engineering (WIE) and IEEE Young Professionals, YP (formerly the Graduate of the Last Decade, GOLD) affinity groups, as well as the Women in Science and Engineering (WISE) organization at the University of Manitoba. Many very useful seminars, tutorials and workshops on current topics in computing and embedded systems have been organized by those organizations in the past.

\subsection{Teaching Teachers}

The IEEE Teachers-In-Service Program (TISP) is intended to reach many high-school students through their teachers. We have been developing workshops for teachers. One of such workshops on smart robotics is being planned for May 2014.

The purpose of the IEEE Engineering Projects in Community Service (EPICS) program is to empower student branches and IEEE YP to work with high school students on community service-related engineering projects. Our current activities on amateur radio, satellites, and unmanned aerial vehicles (UAVs) fall under this category.

\section{INTERNATIONAL ENGAGEMENT}

An international outreach is also important to achieve the intended long-term impact on the future generation of engineering and humanitarian technology professionals. For example, a Space Outreach Panel was organized at the International Space University (ISU) on July 23, 2013, with representatives from NASA, CSA, the Nigerian Space Agency, Israeli Space Agency, and World Space Week. The theme revolved around common challenges and lessons learned from around the world for making space projects tangible to pre-university audiences.

Another example is the inclusion of international students from Mexico in our Space Camp. We are working on including international students from other countries.

Another example included students from Canada and Germany, and professionals from the Netherlands in the YES2 project. Those students participated in a project during the Zero-Gravity Parabolic Flight in Bordeaux, France, June 2006.

We have also been involved in developing linkages to other organizations, through the Canadian Space Society (CSS), Canadian Aeronautics and Space Institute (CASI), Canadian Space Agency (CSA), European Space Agency (ESA), NASA, Russia Space Agency (RSA), the G20 countries, Radio Amateurs of Canada (RAC), Winnipeg Amateur Radio Club (WARC) and others.

\section{Concluding Remarks}

The understanding of the role of technology and engineering in the world is experiencing a serious transformation: from machine-centric to human-centric. Many organizations are being developed to help in the implementation of the new vision. One aspect that has not been addressed fully is how do we change the programs to teach our students to be not only good adopters of the humanitarian technology, but its creators, implementers and maintainers. This calls for a humanitarian engineering education.

This paper presented examples of several activities conducted in Manitoba that could provide an insight of one aspect of the solution.

\section{Acknowledgements}

We would like to thank the Department of Electrical and Computer Engineering at the University of Manitoba for partial financial support of this project.

\section{References}

[1] Bernard Amadei and Robyn Sandekian, "Model of integrating Humanitarian development into engineering education," J. Professional Issues in Engineering Education and Practice, vol. 136, no. 2, pp. 84-92, April 2010.

[2] Bernard Amadei and William A. Wallace, "Engineering for humanitarian development: A socio-techical approach," IEEE Technology and Society Magazine, vol. 28, no. 4, pp. 6-15, Winter 2009.

[3] Allan Collins and Richard Halverson, Rethinking Education in the Age of Technology: The Digital Revolution and Schooling in America. New York, NY: Teachers College Press, 2009, 192 pp. \{ISBN: $0807750026\}$

[4] Witold Kinsner, "Challenges in the design of adaptive, intelligent and cognitive systems," Intern. J. Software Science \& Computational Intelligence, vol. 1, no. 3, pp. 16-35, July-Sept. 2009.

[5] Witold Kinsner, M.G. (Ron) Britton, Jeff Cieszecki, Wayne Ellis, Alan Thoren, Dario Schor, Brian Statham, Greg Linton, Tom Tessier, Rob Striemer, Colleen Flather, Barbara Bowen, and Norman Lee, "A space adventure camp and pre-university outreach," in Proc. CEEA Canadian Engineering Education Conf., CEEC11 (St. John's, NL; 6-8 June 2011), 8 pp., 2011. 
[6] Witold Kinsner, M.D.(Ron) Britton, Dario Schor, Arash Fazel Darbandi, Kris Goodmanson, Cody Friesen, Emily Bashford, "Preliminary experience from the Canadian Satellite Design Challenge," in Proc. Can. Engineering Education Conf., CEEA11 (St. John's, NL; June 6-8, 2011) 6 pp., 2011.

[7] Witold Kinsner and Kalen Brunham, "A multi-tier laboratory scheme in the interfacing for real-time systems course," in Proc. 14th Can. Conf. Computer Engineering Education, CCCEE01 (Fredericton, NB; May 30-June 1, 2001) 64 pp., 2001.

[8] Witold Kinsner, Stephanie English, Curtis Einarson, Bryan Drobot, Kelly Riha, Mohamed Nasri, Rafi Belal, Barry Prentice, and Dale George, "Design of navigation subsystem for a new UAV: A composite of a capstone and research projects," in Proc. 5th Conference of the Canadian Engineering Education Association, CEEA 2014 (Canmore, AB; June 8-11, 2014).

[9] Witold Kinsner and Joseph J. Pear, "Computer-aided Personalized System of Instruction for the virtual classroom," Can. J. Educational Communication, vol. 17, no. 1, pp. 21-36, 1988.

[10] Witold Kinsner and Joseph J. Pear, "Dynamical educational system for the virtual campus," in Technological Innovation Process and the Human Resources, Urs E. Gattiker and Laurie Larwood (eds.), Vol. II. Berlin: Walter de Gruyter, 1990, pp. 201-228. \{ISBN 0-89925-686-4\}

[11] Carl Mitcham and David Muñoz, Humanitarian Engineering. Synthesis Lectures on Engineers, Technology and Society, Vol. 13. San Rafael, CA: Morgan \& Claypool Publishers, 2010, 87 pp. (doi:10.2200/S00248ED1V01Y201006ETS012) \{ISBN-13: 978-1-608-45152-4 pbk; 978-1-608-45151$7 \mathrm{hbk}\}$
[12] Barbara M. Moskal, Catherine Skokan, David Muñoz, and Joan Gosink, "Humanitarian Engineering: Global impacts and sustainability of a curricular effort," Intern. J. Engineering Education, vol. 24, no. 1, pp. 162-174 (13 pp.), January 2008.

[13] Kevin M. Passino, "World-wide education for the humanitarian technology challenge," IEEE Technology and Society Magazine, vol. 29, no. 2, p. 4, Summer 2010.

[14] Kevin M. Passino, "Educating the Humanitarian Engineer," Science and Engineering Ethics, vol. 15, no. 4, pp. 577-600, December 2009.

[15] Joseph J. Pear and Witold Kinsner, "Computer-Aided Personalized System of Instruction: An effective and economical method for long-distance education," Intern. J. Machine Mediated Learning, vol. 2, pp. 213237, 1988.

[16] Jonathan Daniel James Vandersteen, Humanitarian Engineering in the Engineering Curriculum. Doctoral Dissertation. Kingston, Ontario, Canada: Department of Civil Engineering, Queen's University, August 2008, 361 pp. Retrieved April 20, 2014 from http://qspace.library.queensu.ca/dspace/bitstream/1974 /1373/1/VanderSteen_Jonathan_DJ_200808_PhD.pdf? origin=publication_detail

[17] Thomas Tredgold, The Royal Charter of the Institution of Civil Engineers. 1828. Retrieved April 20, 2014 from http://en.wikipedia.org/wiki/Thomas_Tredgold

[18] Beverly Park Woolf, Ivon Arroyo, and Imran A. Zualkernan, "Education technology for the developing world," in Proc. IEEE Global Humanitarian Technology Conference, GHTC11, (Seattle, WA; Oct. 30 2011-Nov. 12011 ) pp. 493-498, 2011. \{ISBN 978$1-61284-634-7\}$ 